\title{
The effect of contextual stimuli on retroactive inhibition'
}

\author{
WILMA GOTTLIEB, CLARK UNIVERSITY \\ MARTIN S. LINDAUER, STATE UNIVERSITY OF NEW YORK, COLLEGE AT BROCKPORT
}

In an $A-B, A-C$ paradigm for investigating retroactive inhibition (RI), two sets of contextual stimuli (colored shapes) surrounded each list. During recall, RI groups were given either the context present during interpolated learning $(I L)$ or the context present during original learning (OL). Through two recall trials but not through relearning $(R L)$, the presence of the $O L$ context reduced $R I$, while the presence of the $I L$ context increased $R I$.

Contextual circumstances under which learning and recall take place have been shown to influence $\mathrm{RI}$ (McGeoch \& Irion, 1952, pp. 448-455; Greenspoon \& Renyard, 1957). When the recall context is the same as OL but different from IL, RI is reduced; RI is increased when the recall context is different from OL but the same as IL. It has also been shown that recall which is not preceded by IL is facilitated by the use of a color/shape context which is consistent with OL circumstances (Saltz, 1963; Birnbaum, 1966). The effect of this specific type of contextual cue on RI has not been investigated. In the present study, it was expected that the previously found effect of context on RI would occur when color-shape cues were used. It was hypothesized that the presence of the original context at recall would reduce $\mathrm{RI}$, while the presence of the interference context would increase RI.

\section{Method}

In an $\mathrm{A}-\mathrm{B}, \mathrm{A}-\mathrm{C}$ paradigm of learning, Ss learned number-nonsense syllable pairs. List contexts were created by surrounding the pairs on $O L, I L$, and recall lists with a common set of colored shapes. Two RI groups recelved a recall test in which the context was elther the same as OL but different from IL (RI-weak) or the same as IL but different from OL (RI-strong). A control group learned and recalled OL under identical contextual conditions. The criterion for OL was one errorless trial; approximately $1.5 \mathrm{~min}$ after OL was completed, IL was presented for 10 trials. During the retention interval from the end of OL to the beginning of recall (20 min for the control group, $11.5 \mathrm{~min}$ for the RI groups), Ss rated cartoons. Recall was tested through one errorless relearning (RL) trial. Two lists, composed of eight number-nonsense syllable pairs, were used equally as OL or IL. The stimulus items, which were identical on both lists, were numbers of high association value scaled by Battig and Spera (Runquist, 1966, p. 497), $\bar{X}=2.97$. The two different sets of nonsense syllable responses were taken from Glaze (Hilgard, 1951, pp. 541-544), ranging from $27-47 \%$ association value, $\overline{\mathrm{X}}=36.75 \%$.
The two responses paired with the same stimulus had the same association value. Intralist similarity was reduced as much as possible. The context for the pairs of each list were either blue rectangles or red ellipses, which surrounded both members of the pair. These two contexts were used equally with each list. A practice list, consisting of eight pairs of common nouns without any surrounding context, was employed. The material was presented on a stoelting memory drum at a 2:2 rate, with an 8 sec intertrial interval. There were three orders for each list, with the starting order randomly assigned to each $S$. The last order of $O L$ and the first order of recall always differed. Stimulus items were pronounced and response Items were spelled. Although Ss were alerted to the presence but not to the purpose of the context, the task of learning and recalling the pairs was emphasized. Ss were 60 volunteer female undergraduates, who had never participated in a verbal learning experiment. The first $30 \mathrm{Ss}$ were randomly assigned to the three groups prior to their appearance in the laboratory; the last $30 \mathrm{Ss}$ were assigned to the various conditions after OL was completed in order to equate the groups on learning.

Results

The mean number of trials required to learn OL for the Control, RI-weak, and RI-strong groups was $15.70,15.85$, and 14.75, respectively. These differences on $O L$ were not significant $(F<1)$, nor were the differences between learning rates for the two lists $(t=1.06$, df $=58, p>.05)$ or for the two contexts $(t<1.00)$ significant on $O L$. The mean number of correct anticipations on the last (tenth) trial of IL, 6.35 and 6.10 for the RI-weak and RI-strong groups, respectively, did not differ significantly $(t<1.00)$. Differences between lists $(t=1.45, d f=58, p>.05)$ and contexts $(t=1.62, d f=58, p>.05)$ on IL were also nonsigniflcant. The mean number of correct responses on the flrst recall trial was $5.95,3.30$, and 2.30 for the Control, RI-weak, and RI-strong groups, respectively. These differences were significant ( $F=40.89$, $\mathrm{df}=2 / 57, p<.01$ ). Indicative of an $\mathrm{RI}$ effect, recall for the Control group was signiflcantly better than both RI-weak $(t=6.13$, df $=38, p<.01)$ and $R I-$ strong $(t=9.56, d f=38, p<.01)$. Indicative of a differential RI effect, recall for RI-weak was signiflcantly better than RI-strong $(t=2.29, d f=38, p<.05)$. The mean trials to relearn the lists to criterion was $3.30,4.85$, and 5.60 for the Control, RI-weak, and RI-strong groups, respectively. These differences were signif- 
icant $(F=4.35, d f=2 / 57, p<.05)$, but showed only an RI effect: Control group's RL was significantly better than both $\mathrm{RI}-$ weak $(\mathrm{t}=2.06, \mathrm{df}=38, \mathrm{p}<.05)$ and $\mathrm{RI}$-strong $(t=2.73, d f=38, p<.02)$. However, a differential $R I$ effect was found on the second recall test (the first RL trial), where the difference between the two RI groups was significant $(t=2.13, d f=38, p<.05)$.

\section{Discussion}

Confirming the hypothesis and in keeping with previous work on the role of contextual factors, RI was greatest when the list context of IL was present at recall (RI-strong), and reduced when the context of OL was present (RI-weak). This difference persisted through the first two test trials. These results may be accounted for by the mechanism of contextual unlearning during IL (McGovern, 1964; Silverstein, 1967), as well as by the presence of a contextual generalized response tendency (GRT) at recall (Newton \& Wickens, 1956; Postman \& Stark, 1962). Since the effect of differential list context on RI was not sustained through RL, unlearning and GRT factors are relatively transient.

References

BIRNBAUM, I. M. Context stimuli in verbal learning and the persistence of associative factors. J. exp. Psychol., 1966, 71, 483-487.

GREENSPOON, J., \& RENYARD, R. Stimulus conditions and retroactive inhibition. J. exp. Psychol, 1957, 53, 55-59.

HILGARD, E. R. Methods and procedures in the study of learning. In S. S. Stevens (Ed.), Handbook of experimental psychology. New Yotk: Wiley, 1951.

McGEOCH, J. A., \& IRION, A. L. The psychology of human learning. (2nd ed.) New York: Longmans, Green, 1952.

McGOVERN, J. B. Extinction of associations in four transfer paradigms. Psychol. Monogr.: Gen. \& Appl., 1964, 78 (16) (Whole No. 593), 21pp. P. 21.

NEWTON, J. M., \& WICKENS, D. D. Retroactive inhibition as a function of the temporal position of interpolated learning. J. exp. Psychol., 1956, 51, 149-154.

POSTMAN, L., \& STARK, K. The role of response sets in tests of unlearning. J. verbal Learn. verbal Behav., 1965, 4, 315-322.

RUNQUIST, W. N. Verbal behavior. In J. B. Sidowski (Ed.), Experimental methods and instrumentation in psychology. New York: McGraw-Hill, 1966.

SALTZ, E. Compound stimuli in verbal learning: Cognitive and sensory differentiation versus stimulus selection. J. exp. Psychol, 1963, 66, $1-5$.

SILVERSTEIN, A. Unlearning, spontaneous recovery, and the partial reinforcement effect in paired-associate learning. $J$. exp. Psychol., $1967,73,15-21$.

Note

1. The data were collected at Cedar Crest College, in fulfillment of the senior author's Independent Study requirement.

\section{Errata}

Marx, M. H., \& Tombaugh, Jo W. The frustration vigor effect (FVE) as a function of number of rewarded barpress trials. Psychon. Sci., 1967, 8, 105-106. In identifying the curves in Figure 1, the open and closed circle points in the legend were reversed.
Sticht, T. G. \& Gibson, R. H. Touch thresholds as a function of onset and offset stimulation. Psychon. Sci., 1967, 8, 255-256. - In the abstract, the positions of the words "application" and "subsequent removal" should be interchanged. 